\title{
Uma nova espécie de Tournefortia L. (Boraginaceae s.l.) para o Nordeste do Brasil
}

\author{
José Iranildo Miranda de Melo'
}

Recebido: 17.07.2006; aceito: 29.03.2007

\begin{abstract}
A new species of Tournefortia L. (Boraginaceae s.l.) from Northeast Brazil). A new species of Tournefortia (Boraginaceae s.l.) morphologically related to T. rubicunda Salzm. ex A.DC., T. andrade-limae J.I.M. Melo, for the state of Paraíba, Northeast Brazil is described. Comments on taxonomic relationships based on the morphology, as well as illustration and reproductive phenology data are presented.
\end{abstract}

Key words: Boraginaceae s.l., Brazil, caatinga vegetation, Tournefortia.

RESUMO - (Uma nova espécie de Tournefortia L. (Boraginaceae s.l.) para o Nordeste do Brasil). Uma nova espécie de Tournefortia (Boraginaceae s.l.) morfologicamente relacionada à T. rubicunda Salzm. ex A.DC., T. andrade-limae J.I.M. Melo, é descrita para o estado da Paraíba, Nordeste do Brasil. São apresentados comentários enfocando afinidades taxonômicas, baseados em morfologia, bem como ilustração e dados de fenologia reprodutiva.

Palavras-chave: Boraginaceae s.l., Brasil, caatinga, Tournefortia.

\section{Introdução}

Tournefortia L. reúne aproximadamente 150 espécies, distribuídas especialmente nas regiões tropicais e subtropicais, e é considerado um dos maiores e mais complexos gêneros da família Boraginaceae s.l. (Gürke 1893) por apresentar plasticidade fenotípica em várias de suas espécies. $\mathrm{O}$ gênero diferencia-se de Cordia L. pelas inflorescências escorpióides com as flores dispostas unilateralmente e pelo estilete inteiro, e de Heliotropium L. s.l., principalmente, pelo hábito lenhoso, aliado ao fruto drupáceo este freqüentemente branco, raramente maculado, vermelho ou alaranjado ou, também, pela corola com lobos reflexos (Gentry 1993).

Caracteriza-se, especialmente, pelo hábito subarbustivo, escandente ou não, ou lianescente. As folhas são simples, alternas ou falsamente opostas. Os frutos drupáceos, portando dois ou quatro lobos, e associados às inflorescências escorpióides, geralmente paniculiformes, parcamente ou densamente ramificadas, laxas ou congestas, constituem os principais caracteres para o reconhecimento das suas espécies.
Dentre os trabalhos clássicos que incluem as representantes de Tournefortia destacam-se: De Candolle (1845), Fresenius (1857) e Gürke (1893). Entretanto, o tratamento mais abrangente para este gênero foi elaborado por Johnston (1930), englobando as espécies dispersas na porção oriental da América do Sul (Brasil, Bolívia, Paraguai, Uruguai e Argentina), as quais foram alocadas em duas seções: Tournefortia sect. Tournefortia e Tournefortia sect. Cyphocyema I.M. Johnst. Embora ainda sejam necessários estudos sistemáticos visando ampliar o conhecimento das suas espécies e discutir as relações entre tais seções e com gêneros afins, o trabalho de Johnston (1930) consiste ainda no tratamento adotado pela maioria dos estudiosos da família.

Tournefortia sect. Cyphocyema possui aproximadamente 20 espécies, com distribuição exclusivamente neotropical, caracterizadas especialmente pela corola com lobos involutos e anteras conatas, aliadas aos frutos 4-lobados portando sementes com embrião curvo. Encontram-se distribuídas, em sua quase totalidade no território brasileiro associadas, sobremaneira, às formações florestais, restingas, caatingas e cerrados. Entretanto, alguns dos seus táxons apresentam problemas de

1. Universidade Federal Rural de Pernambuco, Departamento de Biologia, Área de Botânica, Rua Dom Manoel de Medeiros, s/n, Dois Irmãos, 52171-900 Recife, PE, Brasil/Universidade Federal Rural do Semi-Árido, Departamento de Ciências Vegetais, BR 110, km 47, Bairro Presidente Costa e Silva, 59625-900 Mossoró, RN, Brasil (heliotropium@bol.com.br) 
delimitação, provavelmente refletidos pela plasticidade relacionada ao espectro de distribuição e, consecutivamente, de habitats nos quais se estabelecem. Com base no levantamento executado nos principais herbários brasileiros, especialmente os da região Nordeste, visando à revisão taxonômica de Tournefortia sect. Cyphocyema e, também, por ocasião da elaboração da check-list da família Boraginaceae para a região Nordeste (Melo 2006), verificou-se uma nova espécie, pertencente a esta seção, para o estado da Paraíba, denominada Tournefortia andrade-limae aqui descrita e ilustrada.

\section{Material e métodos}

Este trabalho foi baseado, fundamentalmente, no estudo de coleções pertencentes aos herbários: ALCB, CEPEC, EAN, HST (Herbário Sérgio Tavares, Departamento de Engenharia Florestal, Universidade Federal Rural de Pernambuco), HUEFS, IPA, JPB, MAC, MOSS (Herbário Dárdano de Andrade-Lima, Departamento de Ciências Vegetais, Universidade Federal Rural do Semi-Árido), MUFAL, PEUFR, TEPB e UFP, listados de acordo com Holmgren et al. (2005). A descrição fundamentou-se nas terminologias propostas por Stearn (1973) e Radford et al. (1974). Hickey (1973) e Payne (1978) foram também consultados para a caracterização dos padrões de venação e indumento, respectivamente. São fornecidas descrição e ilustrações contendo os caracteres relevantes para o reconhecimento do táxon ora abordado.

\section{Resultados e Discussão}

Tournefortia andrade-limae J.I.M.Melo, sp. nov. Tipo: BRASIL. Paraíba: São José dos Cordeiros, VI-1997, Braz s.n. (holótipo: IPA53027).

Affinis T. rubicunda, sed foliis brochidodromis, floribus subssessilibus vel pedicellatis, anthera circa $1 \mathrm{~mm}$ longa ovata-triangulari atque ovario lageniformi pubescenti differt.

Figura 1A-E

Arbusto escandente; ramos glabros ou pubérulos com lenticelas acastanhadas. Folhas alternas, curtamente pecioladas; lâmina 3,4-3,5 × 1,1-1,3 cm, membranácea, levemente discolor, ovada, ápice cuspidado, margem inteira a levemente ondulada, ciliada, base arredondada, estrigosa em ambas as faces, venação broquidódroma; pecíolo 3-4 $\mathrm{mm}$ compr., cilíndrico. Inflorescências 2,3-3,7 cm compr., terminais e axilares, escorpióides, densamente ramificadas, paniculiformes, laxas; pedúnculo 0,8-2,7 cm compr., viloso. Flores ca. $4 \mathrm{~mm}$ compr., subsésseis ou evidentemente pedicelada; pedicelo ca. $1 \mathrm{~mm}$ compr. Cálice menor ou algumas vezes alcançando o comprimento da corola; sépalas unidas apenas na base com 2,3-2,5 $\times 0,2-0,4 \mathrm{~mm}$, lanceoladas, pubescentes externamente, com margem ciliada, glabras internamente. Corola 4,4-4,7 mm compr., tubular, vilosa externamente, inclusive na região dos lobos estes com ca. $1 \mathrm{~mm}$ compr., lineares, involutos. Estames subsésseis, inseridos ca. $2 \mathrm{~mm}$ da base do tubo da corola; anteras conatas, ovado-triangulares. Ovário ca. $1 \mathrm{~mm}$ compr., lageniforme, pubescente. Estilete ca. 1,3 mm compr., alargado desde a base até a porção mediana, pubescente. Estigma ca. 0,3 mm compr., cônico na região fértil, levemente bífido no ápice. Frutos não observados.

Esta espécie foi encontrada, até o momento, apenas no município de São José dos Cordeiros, nos Cariris Velhos, estado da Paraíba, associada à vegetação de Caatinga. Coletada somente com flores em junho.

Tournefortia andrade-limae é reconhecida, principalmente, pelas suas folhas arredondadas na base e inflorescências densamente ramificadas. É espécie morfologicamente semelhante à T. rubicunda Salzm. ex A.DC., no entanto, T. andrade-limae possui lâmina foliar com venação broquidódroma, inflorescências densas, flores subsésseis ou evidentemente pediceladas, anteras com ca. $1 \mathrm{~mm}$ compr., ovadotriangulares e ovário lageniforme, pubescente enquanto T. rubicunda apresenta lâmina foliar com venação eucamptódroma, inflorescências laxas, flores sésseis, anteras com ca. $0,8 \mathrm{~mm}$ compr., lanceoladas e ovário obclavado, glabro. O epíteto específico foi atribuído em homenagem ao botânico Dárdano de AndradeLima (In memoriam), da Empresa Pernambucana de Pesquisa Agropecuária (IPA) e da Universidade Federal Rural de Pernambuco (UFRPE).

\section{Agradecimentos}

À Dra. Rita de Cássia de Araújo Pereira, do Herbário IPA, pelo empréstimo da coleção para estudo. À Profa. Dra. Margareth Ferreira de Sales, da Universidade Federal Rural de Pernambuco, pela leitura crítica do manuscrito. A Franck Valdomiro Silva, pela confecção das ilustrações. A Milton Groppo, da Universidade de São Paulo, Ribeirão Preto, pela diagnose latina. A CAPES (Coordenadoria de Aperfeiçoamento de Pessoal de Nível Superior) pela bolsa de doutoramento. 


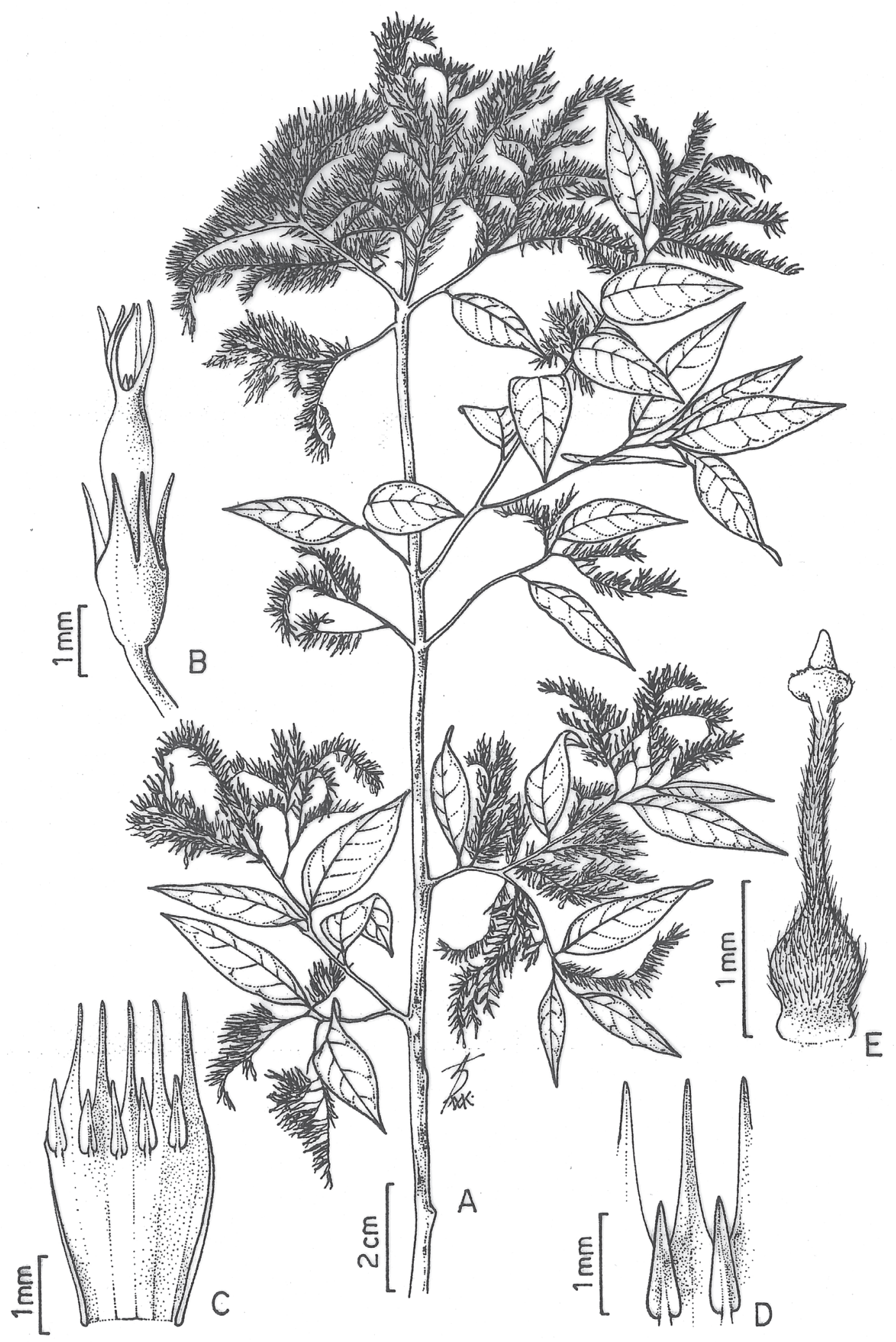

Figura 1. A-E. Tournefortia andrade-limae (Braz s.n., IPA53027). A. Ramo florífero. B. Flor. C. Corola rebatida. D. Detalhe dos lobos da corola evidenciando os estames. E. Gineceu. 


\section{Literatura citada}

De Candolle, A.P. 1845. Borragineae. In: A.P. De Candolle (ed.). Prodromus systematis naturalis regni vegetabilis. Treuffel \& Wurtz, Paris, v. 9, pp. 466-559.

Fresenius, G. 1857. Cordiaceae, Heliotropieae, Borragineae. In: C.F.P. von Martius \& A.G. Eichler (eds.). Flora Brasiliensis. Typographia Regia, Monachii, v. 8, pt. 1, pp. 1-64.

Gentry, A.H. 1993. Boraginaceae. In: A.H. Gentry (ed.). A Field Guide to the families and genera of woody plants of Northwest South America (Colombia, Ecuador, Peru). Washington, DC.

Gürke, M. 1893. Borraginaceae. In: A. Engler \& K. Prantl (eds.). Die natürlichen Pflanzenfamilien. Verlag von Wilhelm Engelmann, Leipzig, v. 4, pt. 3a, pp. 49-96.

Hickey, L.J. 1973. Classification of the architecture of dicotyledonous leaves. American Journal of Botany 60: 17-33.
Holmgren, P.K., Holmgren, N.H. \& Barnett, L.C. 2005. Index Herbariorum. Part 1. The Herbaria of the world. http://sci.web.nybg.org/science2/IndexHerbariorum.as. (acesso em 28.06.2006).

Johnston, I.M. 1930. Studies in Boraginaceae 8: Observations on the species of Cordia and Tournefortia known from Brazil, Paraguay, Uruguay and Argentina. Contributions from the Gray Herbarium of Harvard University 82: 3-89.

Melo, J.I.M. 2006. Boraginaceae. In: M.R.V. Barbosa et al. (eds.). Checklist das Plantas do Nordeste Brasileiro: Angiospermas e Gimnospermas. Ministério da Ciência e Tecnologia, Brasília. pp. 49.

Payne, W.W. 1978. A glossary of plant hair terminology. Brittonia 30: 239-255.

Radford,A.E., Dickison, W.C., Massey, J.R. \& Bell, C.R. 1974. Vascular Plant Systematics. Harper \& Row, New York.

Stearn, W.T. 1973. Botanical Latin. Redwood Press Limited Trowbridge, Wiltshire. 